\title{
Determinants of Breast-Feeding Initiation Time among Newborns Delivered in a Tertiary Baby Friendly Health Facility in Enugu, Nigeria
}

\author{
Christopher Bismarck Eke ${ }^{1}$, Israel Odutola Odetunde ${ }^{1}$, Samuel Nkachukwu Uwaezuoke1, \\ Uzoamaka Vivian Muoneke ${ }^{1}$, Nnamdi Benson Onyire ${ }^{2}$, Uchenna Ekwochi ${ }^{3}$, \\ Chika Nwanma Onwasigwe ${ }^{4}$
}

\footnotetext{
${ }^{1}$ Department of Paediatrics, College of Medicine, University of Nigeria/Teaching Hospital, Ituku-Ozalla, Enugu, Nigeria ${ }^{2}$ Department of Paediatrics, College of Medicine, Ebonyi State University, Abakaliki/Federal Teaching Hospital, Abakaliki, Ebonyi State, Nigeria

${ }^{3}$ Department of Paediatrics, College of Medicine, Enugu State University of Science and Technology (ESUT)/ESUT Teaching Hospital, Park Lane, Enugu, Nigeria

${ }^{4}$ Department of Community Medicine, College of Medicine, University of Nigeria/Teaching Hospital, Ituku-Ozalla, Enugu, Nigeria

Email: *vizym@yahoo.com, *uzoamakamuoneke@gmail.com
}

How to cite this paper: Eke, C.B., Odetunde, I.O., Uwaezuoke, S.N., Muoneke, U.V., Onyire, N.B., Ekwochi, U. and Onwasigwe, C.N. (2019) Determinants of Breast-Feeding Initiation Time among Newborns Delivered in a Tertiary Baby Friendly Health Facility in Enugu, Nigeria. Open Journal of Pediatrics, 9, 47-61. https://doi.org/10.4236/ojped.2019.91006

Received: February 1, 2019

Accepted: March 15, 2019

Published: March 18, 2019

Copyright $\odot 2019$ by author(s) and Scientific Research Publishing Inc. This work is licensed under the Creative Commons Attribution International License (CC BY 4.0).

http://creativecommons.org/licenses/by/4.0/

\section{c) (i) Open Access}

\begin{abstract}
Background: The importance of early breastfeeding initiation to both the mother and infant is enormous as it reduces the likelihood of neonatal mortality as well as maternal postpartum haemorrhage. The objectives of the study were to assess the prevalence and determinants of correct breastfeeding initiation time among newborns delivered at the University of Nigeria Teaching Hospital, Enugu. Methods: This was a cross sectional descriptive study. Relevant maternal and new-born birth characteristics were obtained using a pretested semi-structured questionnaire. Data were analyzed using SPSS version 20.0. Multivariate logistic regression was used to determine the factors that are significantly associated with correct breastfeeding initiation time with the level of significance set at $\mathrm{p}<0.05$. Results: A total of 321 mother-newborn pairs were studied. 86 (26.8\%) of the respondents correctly initiated breastfeeding within 1 hour of delivery. Planned pregnancy, pre-pregnancy decision on infant feeding options, primiparity, vaginal delivery and breast milk as first food given to the neonate post-delivery were associated with increased likelihood of correct breastfeeding initiation time. Conclusion: Correct breastfeeding initiation time among respondents is low. Planned pregnancy, pre-pregnancy decision on infant feeding option before pregnancy, primiparity, vaginal delivery and breast milk as first food given to the neonate after delivery were associated with having correct breastfeeding
\end{abstract}


initiation time among respondents. Efforts should be made to complement Baby Friendly Hospital Initiative with baby friendly community initiative in order to improve the rate of correct breastfeeding initiation time in our setting.

\section{Keywords}

Breastfeeding Initiation Time, Newborns, Baby Friendly Hospital Initiative

\section{Introduction}

Breastfeeding is a natural way of support for the optimal growth and development of young children particularly infants. The United Nations Children's Fund (UNICEF) and World Health Organization (WHO) have jointly recommended exclusive bread feeding (EBF) for the first 6 months of life and breastfeeding continued up to 2 years and beyond. Although, it is the desirable, form of infant feeding, partial breastfeeding as well as breastfeeding for shorter periods of time are also of benefits [1].

The benefits of breastfeeding towards the promotion of child health and development as well as in later life are well established. The first milk, colostrum contains varieties of immunologic and nutritious properties [2], with diverse functions including protection of the newborns from infections such as diarrhoeal disease [3], pneumonia [4], neonatal sepsis [5], among others in addition to the early normalization of intestinal physiologic functions.

The WHO and UNICEF have jointly launched and sustained the "Ten Steps to successful breastfeeding" under the framework of the Baby Friendly Hospital Initiative (BFHI) with the objectives of protecting, promoting and supporting breastfeeding which are the special role of maternity services. The chief target of the $4^{\text {th }}$ step of the "Ten steps to successful breastfeeding" of the BFHI is to ensure that every health facility providing maternity services and care for newborn infants should help mothers initiate breastfeeding within a half hour of birth following vaginal delivery [6].

Breastfeeding initiation within an hour of delivery has been adjudged the desired form of feeding following its link with reduced neonatal mortality indices [7] [8]. Hence the provision of maternal breast milk to infants within one hour of birth is referred to as "early initiation of breastfeeding" and the WHO has recommended that in order to ensure early breastfeeding initiation newborns should be placed in skin to skin contact with their mothers soon after birth for at least 60 minutes [9].

Early breastfeeding initiation is beneficial to both the mothers and the infants. To the mother early initiation of EBF helps post-partum hemorrhage to be controlled with secreted oxytocin hormone from the anterior pituitary gland [10], while in children mortalities have been reported to be prevented in 42 high mortality countries through increased breastfeeding rates [11] [12]. 
A recent study suggests that fact that delayed initiation of breastfeeding is a risk factor for neonatal deaths [6] [7]. However, increasing the proportion of infants that receive breast milk within the first 24 hours of life has been associated with reduced neonatal mortality to about $16 \%$ [6] [7].

Currently the exclusive breastfeeding rate in Nigeria is at its lowest ebb of $17 \%$ among children less than 6 months of age with a median duration of 0.5 months [13].

It has been shown that when clinicians and other health workers are positive about the benefits of breastfeeding particularly pediatricians whose roles are key in the field of child health as counselors, educators and opinion builders; mothers are more likely to practice EBF [14] [15], including its early initiation.

Thus study aimed to evaluate prevalence and determinants of correct breastfeeding initiation time among newborns delivered at the University of Nigeria Teaching Hospital, Ituku-Ozalla, Enugu, Nigeria.

\section{Methods}

This was a cross sectional study conducted in the labour ward, postnatal wards and New Born Special Care Unit (NBSCU) of University of Nigeria Teaching Hospital (UNTH) ltuku-Ozalla, Enugu from $1^{\text {st }}$ April, 2014 to $10^{\text {th }}$ June, 2016.

All eligible mothers with their respective newborn infant pairs who were delivered in the hospital and consented during the study period were consecutively recruited during the study period.

The inclusion criteria for the study were all mothers who were delivered in the hospital at the time of the study and consented to the study.

Mother-infant pairs were excluded from the study if mothers declined to consent for the study or the infant was born before arrival to the hospital.

Ethical approval for the study was obtained from the Health Research Ethics Committee of UNTH, Enugu.

Informed consent was obtained from all eligible mothers. Respondents were recruited from the labour ward, post-natal ward or New Born Special Care Unit of the hospital.

\subsection{Study Participation and Data Collection}

Questionnaire for the study was adapted from previous similar studies [8] [11] and was pretested prior to the commencement of the study among a sample of 20 mothers of which $95 \%$ found the content unambiguous.

Relevant information included in the study questionnaire were: maternal age, marital status, maternal and paternal education, maternal and paternal occupation, maternal birth characteristics (parity, mode of delivery-vaginal or caesarean section, antenatal care attendance in the index pregnancy, and maternal medical/psychological illness in the index pregnancy.

Also the social and medical characteristics of the newborns were collected including: infant's post-natal medical condition, gestational age at birth, gender of 
baby, birth weight, and history of admission to the New-born Special Care Unit and the indication (s) for the hospitalization thereof.

The social class of each child was assessed using the criteria proposed by Oyedeji [16] in Ilesha, Nigeria with classification into five classes (social classes I to V). Here the social class of each child was determined based on the occupational status and highest educational attainment of the parents. The scores were summed and the mean (approximated to the nearest whole number) obtained. The mean score was used to assign the child to one of the socio-economic classes ( 1 to $\mathrm{V}$ ). The social classes of the subjects were further stratified into upper (social classes I and II), middle (social class III) and lower (social classes IV and V).

\subsection{Definition of Term}

\section{Early Initiation of Breastfeeding}

Correct breastfeeding initiation time was regarded as maternal initiation of breastfeeding within 1 hour post-delivery [7] [8].

\subsection{Statistical Analysis}

Data were analyzed using the statistical package for Social Sciences, (SPSS) Windows Programme (SPSS Inc, Chicago, IL, USA) version 20.0. Chi square test was used to compare the proportions. Bivariate analysis was done and variables that showed significant level of less than 20 (i.e. $\mathrm{p}<0.20$ ) were in-put into the regression model.

The multivariate logistic regression model was used to determine the factors among parity, mode of delivery, post-natal medical history of newborns, planned pregnancy, maternal medical illness in the index pregnancy, gestational age at birth, birth weight, infant feeding decision made prior to conception and first food given to the newborn that actually predicted correct breastfeeding initiation within one hour of delivery, with the level of statistical significance set at $\mathrm{p}<0.05$

\section{Results}

A total of three hundred and twenty-one (321) mother and neonatal pairs were recruited and interviewed.

One hundred and fifty nine (49.5\%) of the mothers were within the 20 to 29 years age bracket, and 315 (98.1\%) were married.

Two hundred and eighteen respondents (67.9\%) had tertiary education while $84(26.2 \%)$ had at least secondary education. Most of the mothers belonged to social classes IV and V, accounting for 135 (42.1\%) of the total respondents as shown in Table 1.

In Table 2, 181 (56.4\%) of the respondents were multiparous mothers while 128 (39.9\%) were primiparous. $312(97.2 \%)$ respondents had adequate attendance at antenatal clinic/care in the index pregnancy while 190 (59.2\%) were delivered vaginally. 
Table 1. Socio-demographic characteristics of study subjects.

\begin{tabular}{ccc}
\hline Characteristics & Frequency $(\mathrm{N}=321)$ & Percent $(\%)$ \\
\hline Age of mother: & 4 & 1.3 \\
$<20$ years & 159 & 49.5 \\
$20-<30$ & 148 & 46.1 \\
$30-<40$ & 10 & 3.1 \\
$\geq 40$ & & \\
Marital Status: & 315 & 98.1 \\
Married & 3 & 0.9 \\
Widow/Widower & 2 & 0.6 \\
Single Mother & & \\
Maternal Educational level: & 18 & 5.6 \\
Primary & 84 & 26.2 \\
Secondary & 218 & 67.9 \\
Tertiary & & \\
Social Economic Class: & 34 & 10.6 \\
1 & 61 & 15.0 \\
2 & 91 & 28.3 \\
3 & 93 & 29.0 \\
4 & 42 & 13.1 \\
5 & &
\end{tabular}

Table 2. Maternal birth characteristic.

\begin{tabular}{|c|c|c|}
\hline Characteristics & Frequency $(\mathrm{N}=321)$ & Percent (\%) \\
\hline \multicolumn{3}{|l|}{ Parity: } \\
\hline Primiparous & 140 & 43.6 \\
\hline Multiparous & 181 & 56.4 \\
\hline \multicolumn{3}{|l|}{ Planned Pregnancy: } \\
\hline Yes & 253 & 78.8 \\
\hline No & 68 & 21.2 \\
\hline \multicolumn{3}{|c|}{ Mode of Delivery in index pregnancy: } \\
\hline Vaginal Delivery & 190 & 59.19 \\
\hline Caesarean section & 131 & 40.81 \\
\hline \multicolumn{3}{|c|}{ Attendance to Antenatal Care in index pregnancy: } \\
\hline Yes & 312 & 97.2 \\
\hline No & 9 & 2.8 \\
\hline \multicolumn{3}{|c|}{ Maternal Medical Illness: } \\
\hline Yes & 69 & 21.5 \\
\hline No & 252 & 78.5 \\
\hline \multicolumn{3}{|c|}{ Interval since last delivery (in months): } \\
\hline $1^{\text {st }}$ pregnancy & 128 & 39.9 \\
\hline$<12$ months & 17 & 5.3 \\
\hline $12-<24$ & 105 & 32.7 \\
\hline$>24$ & 71 & 22.1 \\
\hline \multicolumn{3}{|c|}{ Maternal psychological Illness: } \\
\hline Yes & 12 & 3.7 \\
\hline No & 309 & 96.3 \\
\hline
\end{tabular}


Most of the mothers were stable in the post-delivery period with no significant medical illnesses reported in 252 (78.5\%).

Two hundred and seventy $(84.1 \%)$ of the newborns studied were medically stable while 51 (15.9\%) were admitted into the NBSCU for different medical conditions post-partum.

One hundred and seventy five (54.5\%) were males and majority of the neonates were of normal birth weight, 281 (87.5\%) weighed up to $2.5 \mathrm{~kg}$ or more.

In general $86(26.8 \%)$ of the respondent mothers correctly indicated breastfeeding within 1 hour of delivery.

Various indications for admission of the 51 sick neonates to the NBSCU were: perinatal asphyxia $21(41.2 \%)$ neonatal jaundice 12 (23.5\%), prematurity/low birth weight, 9 (17.6\%), neonatal infections 5 (9.8\%) and respiratory distress syndrome $4(7.8 \%)$ as shown in Table 3.

On the test of association between early breastfeeding initiation time and the various maternal and newborn characteristics: parity $(\mathrm{p}=0.000)$, mode of delivery $(0.000)$, postnatal medical history of newborn $(\mathrm{p}=0.001)$, breastfeeding as first food given to the newborn and the decision of the infant feeding made by the couple/mother pre-pregnancy showed statistical significance $(\mathrm{p}<0.05)$ (Table 4).

Further statistics using bivariate analysis was done. The maternal and newborn characteristics/variables whose bivariate analysis showed a significant level

Table 3. Clinical characteristics of the newborns.

\begin{tabular}{ccc}
\hline Characteristics & Frequency $(\mathrm{N}=321)$ & Percent (\%) \\
\hline Postnatal Medical History: & 270 & 84.1 \\
Normal/Stable & 51 & 15.9 \\
Admitted to NBSCU & & \\
Gestational Age at Birth: & 35 & 10.9 \\
Preterm & 286 & 89.1 \\
Term/Post Term & & \\
Gender of Baby: & 175 & 54.5 \\
Male & 146 & 45.5 \\
Female & & \\
Birth Weight & 40 & 12.5 \\
$<2.5$ kg & 281 & 87.5 \\
$>2.5$ kg & $(\mathrm{n}=51)$ & \\
Perinatal asphyxia & 21 & 41.2 \\
Neonatal Jaundice & 12 & 23.5 \\
Prematurity/LBW & 9 & 17.6 \\
Neonatal infections & 5 & 9.8 \\
Respiratory distress syndrome & 4 & 7.8 \\
\hline
\end{tabular}

Key: NBSCU: Newborn Special Care Unit; LBW: low birth weight. 
Table 4. Association between breastfeeding initiation time and maternal and newborn characteristics.

\begin{tabular}{|c|c|c|c|c|}
\hline \multirow[b]{2}{*}{ Characteristics } & Breastfeeding & Initiation & \multirow[b]{2}{*}{$\mathrm{X}^{2}$} & \multirow[b]{2}{*}{ P-value } \\
\hline & $\begin{array}{l}\geq 2 \text { hours } \\
(n=86)\end{array}$ & $\begin{array}{l}>2 \text { hours } \\
(\mathrm{n}=235)\end{array}$ & & \\
\hline \multicolumn{5}{|l|}{ Maternal Education: } \\
\hline Primary & 3 & 15 & 1.079 & 0.583 \\
\hline Secondary & 24 & 60 & & \\
\hline Tertiary & 59 & 160 & & \\
\hline \multicolumn{5}{|l|}{ Social Class } \\
\hline 1 & 8 & 26 & 3.600 & 0.463 \\
\hline 2 & 19 & 42 & & \\
\hline 3 & 20 & 71 & & \\
\hline 4 & 24 & 69 & & \\
\hline 5 & 15 & 27 & & \\
\hline \multicolumn{5}{|l|}{ Parity: } \\
\hline Primiparous & 23 & 117 & 13.594 & 0.001 \\
\hline Multiparous & 63 & 118 & & \\
\hline \multicolumn{5}{|l|}{ Mode of delivery: } \\
\hline Normal/vaginal & 73 & 117 & 33.631 & 0.001 \\
\hline Caesarean section & 13 & 118 & & \\
\hline \multicolumn{5}{|c|}{$\begin{array}{l}\text { Postnatal Medical History } \\
\text { of the newborn: }\end{array}$} \\
\hline Normal/stable & 82 & 188 & 11.099 & 0.001 \\
\hline Admitted to NBSCU & 4 & 47 & & \\
\hline \multicolumn{5}{|l|}{ Parental Harmony: } \\
\hline Harmonious & 83 & 233 & 0.077 & 0.602 \\
\hline Disharmony & 1 & 2 & & \\
\hline \multicolumn{5}{|l|}{ Planned pregnancy: } \\
\hline Yes & 62 & 191 & 3.180 & 0.054 \\
\hline No & 24 & 44 & & \\
\hline \multicolumn{5}{|l|}{$\begin{array}{l}\text { Maternal Social History } \\
\text { (smoking): }\end{array}$} \\
\hline Yes & 3 & 8 & 0.001 & 0.605 \\
\hline No & 83 & 226 & & \\
\hline \multicolumn{5}{|l|}{ Maternal alcohol use: } \\
\hline Yes & 12 & 39 & 0.329 & 0.350 \\
\hline No & 74 & 196 & & \\
\hline \multicolumn{5}{|l|}{$\begin{array}{l}\text { Maternal History of } \\
\text { Intravenous Drug Use: }\end{array}$} \\
\hline Yes & 0 & 3 & 1.108 & 0.391 \\
\hline No & 86 & 232 & & \\
\hline
\end{tabular}




\section{Continued}

Maternal Medical Illness in the index pregnancy:

$\begin{array}{ccccc}\text { Yes } & 13 & 56 & 2,833 & 0.060 \\ \mathrm{Bi} & 73 & 176 & & \end{array}$

Gestational age at birth:

$\begin{array}{lcccc}\text { Preterm } & 6 & 29 & 1.894 & 0.118 \\ \text { Term/Post term } & 80 & 205 & & \\ \text { Gender of baby: } & & & & \\ \quad \text { Female } & 42 & 103 & 0.590 & 0.260 \\ \quad \text { Male } & 44 & 131 & & \\ \text { Birth weight: } & & & & \\ \quad<2.5 \mathrm{~kg} & 7 & 30 & 1.401 & 0.162 \\ \geq 2.5 \mathrm{~kg} & 79 & 202 & & \end{array}$

$1^{\text {st }}$ food given to Newborn:

$\begin{array}{ccc}\text { Breast milk } & 73 & 76 \\ \text { Formula } & 2 & 64 \\ \text { Glucose water } & 8 & 70 \\ \text { Others } & 3 & 24\end{array}$

Antenatal Care in index pregnancy:

\section{Yes \\ No}

Infant Feeding made before pregnancy:

Yes

No

Maternal Psychological Illness in Pregnancy/Peurperium:

$\begin{array}{lcccc}\text { Yes } & 1 & 11 & 2.165 & 0.123 \\ \text { No } & 85 & 224 & & \end{array}$

${ }^{*}$ EBF: Exclusive breastfeeding as defined by the World health organization is feeding of the infant only breast milk and no other liquids or solids except for drops or syrups consisting of vitamins, mineral supplements, or medicines [41].

of less than 20 percent (i.e. $\mathrm{p}<0.20$ ) were in-put into the multivariate logistic regression model.

Primiparity, vaginal delivery, planned pregnancy, breastfeeding as first feeding given and infantfeeding decision made before pregnancy added significantly to the model/prediction table (Table 5).

The odds of having the correct time of initiation of breastfeeding is 5.3 times greater for breastfed babies as opposed to formula fed/other fed babies. The odds of commencing breastfeeding on time was also 2.67 times greater for those 
Table 5. Predictors of correct breastfeeding initiation time among study babies.

\begin{tabular}{|c|c|c|c|c|}
\hline \multirow[t]{2}{*}{ Variable } & \multirow{2}{*}{$\begin{array}{l}\text { Odds } \\
\text { ratio }\end{array}$} & \multicolumn{2}{|c|}{$\begin{array}{l}\text { 95\% Confidence interval } \\
\text { for odds ratio }\end{array}$} & \multirow{2}{*}{ P-value } \\
\hline & & Lower limit & Upper limit & \\
\hline \multicolumn{5}{|l|}{ Parity } \\
\hline Primiparous & 1.948 & 1.038 & 3.650 & $0.038^{*}$ \\
\hline Multiparous & 1 & & & \\
\hline \multicolumn{5}{|l|}{ Mode of delivery } \\
\hline Normal/vaginal & 0.163 & 0.076 & 0.350 & $0.001^{\star}$ \\
\hline Caesarean/instrumental & 1 & & & \\
\hline \multicolumn{5}{|l|}{$\begin{array}{l}\text { Postnatal medical history of } \\
\text { newborn }\end{array}$} \\
\hline Normal/stable & 0.293 & 0.058 & 1.480 & 0.138 \\
\hline Admitted to NBSCU & 1 & & & \\
\hline \multicolumn{5}{|l|}{ Planned pregnancy } \\
\hline Yes & 0.453 & 0.219 & 0.930 & $0.033^{*}$ \\
\hline No & 1 & & & \\
\hline \multicolumn{5}{|l|}{$\begin{array}{l}\text { Maternal medical illness in } \\
\text { index pregnancy }\end{array}$} \\
\hline Yes & 0.980 & 0.438 & 2.190 & 0.960 \\
\hline No & 1 & & & \\
\hline \multicolumn{5}{|l|}{ Gestational age at birth } \\
\hline Before 37 weeks/Preterm & 1.113 & 0.318 & 3.89 & 0.866 \\
\hline After 37 weeks & 1 & & & \\
\hline \multicolumn{5}{|l|}{ Birth weight } \\
\hline$<2.5 \mathrm{~kg}$ & 1.004 & 0.277 & 3.640 & 0.996 \\
\hline$\geq 2.5 \mathrm{~kg}$ & 1 & & & \\
\hline \multicolumn{5}{|l|}{ First food given } \\
\hline Breast milk & 5.307 & 2.706 & 10.400 & $0.001^{*}$ \\
\hline Formula feeding and others & 1 & & & \\
\hline \multicolumn{5}{|l|}{$\begin{array}{l}\text { Infant feeding decision made } \\
\text { before pregnancy }\end{array}$} \\
\hline Yes & 2.670 & 1.116 & 6.380 & $0.027^{\star}$ \\
\hline No & 1 & & & \\
\hline \multicolumn{5}{|l|}{ Maternal psychological illness } \\
\hline Yes & 0.552 & 0.096 & 3.180 & 0.506 \\
\hline No & 1 & & & \\
\hline
\end{tabular}

*Statistically significant.

babies where infant feeding decision was made before pregnancy and 1.9 times higher for primiparous women when compared with multiparous women. The odds of having correct initiation time of breastfeeding was 6.13 times less for ba- 
bies delivered by Caesarean section or instrumental delivery and 2.2 times less in situations where the pregnancy was not planned.

In other words, breastfeeding of babies, making decision on infant feeding options before pregnancy and primparity were associated with an increase in having the correct time of initiation of breastfeeding. Conversely, assisted delivery (Caesarean section or instrumental delivery) and unplanned pregnancy were associated with a reduction in the likelihood of having a correct commencement time of breastfeeding.

\section{Discussion}

From the current study, 86 (26.8\%) out of the 321 mothers studied correctly initiated breastfeeding within one hour of delivery as recommended by the UNICEF/WHO. This rate is low as it falls within the zero to 29 percent bracket adjudged by the WHO as low [11]. It is also well below the Nigerian national prevalence of 40 percent in babies born in urban areas as well as 29 percent among those delivered in rural areas [17]. This prevalence is also much lower than the reports from some countries in sub-Saharan Africa and other developed countries including Kenya, Gambia, Cambodia, New Zealand and Italy [18] [19] [20] [21].

This reported low rate of correct breastfeeding initiation time as reported in the current study is coming at a time when the Nigerian recorded rate of $17 \%$ is regarded as one of the least exclusive breastfeeding globally [17].

It has been reported that the low rates of correct BFI time and EBF in Nigeria could be addressed by complementing and sustaining the BFHI with Baby Friendly Community Initiative (BFCI) as has been demonstrated in Kenya which currently has one of the highest EBF rate of 97\% [19]. However, it is also important to note that a lot of inconsistent definitions of correct breastfeeding initiation time abound in the literature making comparison of the standard timing unreliable [22].

Timely BFI in newborns has been shown to have protective effects on the neonatal morality index within the first 28 days of life including overall neonatal mortality rate; infections related deaths, and low birth weights among other benefits as well as maternal health [22].

The WHO has recommended that all mothers should initiate timely breastfeeding, with health workers assisting mothers to ensure that newborn babies are placed in skin-to-skin contacts with their mothers within one hour of birth in order to achieve this goal. Also mothers should recognize the cues of their newborns readiness to breastfeed. All of these efforts are geared towards successful and timely initiation and sustenance of exclusive breastfeeding [1] [7] [22].

From the current study various maternal and newborn birth characteristics were significantly found to impact on timely breastfeeding initiation-planned pregnancy, parity, infant decision made before pregnancy, mode of maternal delivery, neonatal medical illness and breastfeeding as first food given to the new- 
born.

Currently, it appears that the efforts of the BFHI which targets the mothers presenting to the designated health facilities is not meeting up with the desired goals in our setting. Hence, complementing the BFHI with Baby Friendly Community Initiative (BFCI) may be the step in the right direction for many developing nations including Nigeria struggling to achieve this goal.

Such collaboration has resulted in huge EBF success elsewhere as the BFCI is community driven with local involvement, training of mothers' support groups in the community with close links to the health facilities and applying messages obtained from the community interviews of the residents [18].

Mothers who planned their pregnancies as well as made the decisions to breastfeed their babies prior to achieving pregnancy were more likely to correctly initiate BF on time if given the right family and health facility support as reported in the current study. Various workers working independently had reported that mothers who planned and made decisions to breastfeed their babies are more likely to initiate breastfeeding early [23] [24] [25] [26].

Some researchers had shown that the support a mother receives from health workers can influence her decision on whether or not to initiate breastfeeding timely. Forster and colleague [27], showed that mothers should be encouraged by health workers to breastfeed immediately after birth, while efforts should be made to rightly identify those with higher risk of not successfully initiating and continuing breastfeeding and offer them extra support.

From the current study the odds of correctly initiating breastfeeding timely among mothers was 1.9 times higher for primiparous compared with multiparous mothers. The relationship between parity and birth order and breastfeeding has been found to be inconsistent among previous studies [28] [29] [30]. While some workers [28] [29] reported that primiparous mothers were more likely to initiate EBF timely and more likely to continue breastfeeding; other researchers documented the reverse, pointing that multiparity was significantly associated with early/correct initiation and sustained breastfeeding possibly from their past experiences [28] [30], while Ekstrom et al. [31] and Guo and co-workers [32] found no associations.

Also the odds of having correct initiation time of breastfeeding was 6.13 times less for babies delivered by caesarean section or instrumental delivery compared to those delivered vaginally. Similar findings have been corroborated by previous workers [33] [34]. Operative delivery has great psychological impact not only limited to the patient and her family, but sometimes on the attending physician who could become less motivated to encourage the mother to initiate breastfeeding early combined with the effects of anaesthesia on both the mother as well as on the newborn [33] [34]. However, this is in contrast to mothers who had vaginal deliveries, most of whom had demonstrated early and timely initiation of breastfeeding of their newborns as the process of normal vaginal delivery increases the physiological stimulation of milk production and therefore are more likely to have enough milk and initiate breastfeeding early [35]. 
Various maternal as well as newborn medical conditions could adversely affect early initiation of breastfeeding in the newborns. Such factors include prematurity, low birth weight, infections, congenital abnormalities, prenatal asphyxia among others. Mother with healthy babies are more likely to initiate breastfeeding timely compared with those who had sick newborns [22] [36].

Mothers who decided to practice exclusive breastfeeding before achieving pregnancy started their babies on breastmilk first and early as observed in the current study. Mothers who intended or practiced pre-lacteal feeding with formula milk, glucose water or whatever in their newborns first were more likely not to initiate breastfeeding early as it is when the newborn begins to suckle the maternal nipples that proper breast milk let down is established [37] [38] [39].

Maternal education as well as social class was not significantly associated with timely initiation of breastfeeding in the current study. This is in contrast to the findings by previous workers [25] [38] [40], that women with higher educational status were more likely to initiate and continue breastfeeding in their infants. This could partly be due to the fact that majority of the respondents in the current study had higher educational attainment.

\section{Conclusions}

In conclusion, the timely breastfeeding initiation rate of 26.8 percent among mothers in the current study is adjudged to be low in accordance with the World Health Organization standards.

Planned pregnancy, making decision of infant feeding option before pregnancy, primiparity, vaginal delivery, breastfeeding as the first food given to the neonate after delivery were associated with having the correct timing of breastfeeding initiation among respondents.

Efforts should be made to strengthen BFHI and complement it with Baby Friendly Community Initiative in order to improve the rate of correct breastfeeding initiation time in our setting to save lives.

\section{Conflicts of Interest}

The authors declare no conflicts of interest regarding the publication of this paper.

\section{References}

[1] Agostoni, C., Braegger, C., Decsi, T., Kolacek, S., Koletzko, B., Michelson, K.F., et al. (2009) Breastfeeding: A Commentary by the ESPGHAN Committee on Nutrition. Journal of Pediatric Gastroenterology and Nutrition, 49, 112-125. https://doi.org/10.1097/MPG.0b013e31819f1e05

[2] Gartner, L.M., Morton, J., Lawrence, R.A., Naylor, A.J., Naylor, A.J., O’Hare, D., et al. (2005) Breastfeeding and the Use of Human Milk. Pediatrics, 115, 496-506. https://doi.org/10.1542/peds.2004-2491

[3] Lamberti, L.M., Fischer Walker, C.L., Noiman, A., Victoria, C. and Black, R.E. (2011) Breastfeeding and the Risk for Diarrhea Morbidity and Mortality. BMC Pub- 
lic Health, 11, S15. https://doi.org/10.1186/1471-2458-11-S3-S15

[4] Victoria, C.G. (1996) Infection and Disease: The Impact of Early Weaning. Food and Nutrition Bulletin, 17, 390-396. https://doi.org/10.1177/156482659601700421

[5] Bhutta, Z.A. and Yusuf, K. (1997) Early Onset Neonatal Sepsis in Pakistan: A Case Control Study of Risk Factors in a Birth Cohort. American Journal of Perinatology 14, 577-581. https://doi.org/10.1055/s-2007-994338

[6] WHO (2018) Evidence for the Ten Steps to Successful Breastfeeding. http://www.who.int/nutrition/publication/evidence_ten_step_eng.pdf

[7] Edmond, K.M., Zandoh, C., Quigley, M.A., Amanga-Etego, S., Owusu-Agyei, S. and Kirkwood, B.R. (2006) Delayed Breastfeeding Initiation Increases Risk of Neonatal Mortality. Pediatrics, 117, e380-e386. https://doi.org/10.1542/peds.2005-1496

[8] Alebei, A., Dejuru, G., Mullu, G., Abebe, N., Gualu, T., Eshetie, S., et al. (2017) Timely Initiation of Breastfeeding and Its Association with Place in Ethiopia: A Systematic Review and Meta-Analysis. International Breastfeeding Journal, 12, 44. https://doi.org/10.1186/s13006-017-0133-x

[9] World Health Organization (2016) E-Library of Evidence for Nutrition Action (eLEMNA). http://www.who.int/elema/littles/early_breastfeeding/en/

[10] Orun, E., Yalcin, S.S., Madenga, Y., Ustunyort-Eras, Z., Kutluk, S. and Yurdakok, K. (2010) Factors Associated with Breastfeeding Initiation Time in a Baby-Friendly Hospital. Turkish Journal of Pediatrics, 52, 10-16.

[11] Jones, A., Steketee, R.W., Black, R.E., Bhutta, Z.A. and Morris, S.S. (2006) Bellagio Child Survival Study Optimal Breastfeeding among Children in the Developing World: A Global Ecological Risk Assessment. Public Health Nutrition, 9, 675-685.

[12] Lauer, J.A., Betran, A.P., Barros, A.J.D. and de Onis, M. (2006) Deaths and Years of Life Lost Due to Sub-Optimal Breastfeeding among Children in the Developing World: A Global Ecological Risk Assessment. Public Health Nutrition, 9, 675-685. https://doi.org/10.1079/PHN2005891

[13] Nigeria Demographic and Health Survey (2013).

[14] Igbuzor, O. (2010) Review of MDGs in Nigeria: Emerging Prentices for a Post 2015 Development Agenda.

http://www.opinionnigeria.com/transition-from-mdgs-to-sdgs-in-nigeria-by-otive-i gbuzor/\#sthash.g83bTgr6.dpbs

[15] Taveras, E.M., Li, R., Grummer-Strawn, L., et al. (2004) Opinion and Practices of Clinicians Associated with Continuation of Exclusive Breastfeeding. Pediatrics, 113, 3283-3290. https://doi.org/10.1542/peds.113.4.e283

[16] Oyedeji, G.A. (1985) Socio-Cultural Backgrounds of Hospitalized Children in Ilesha. Nigerian Journal of Paediatrics, 12, 111-117.

[17] National Population Commission (NPC) (Nigeria) and ICF International (2014) Nigeria Demographic and Health Survey 2013. NPC and ICF International, Abuja and Rockville.

[18] Ekanem, E.E. and Fajola, A.O. (2016) Need for Baby Friendly Community Initiative to Improve the Low Exclusive Breastfeeding Rates in Nigeria. Nigerian Journal of Paediatrics, 43, 229-230. https://doi.org/10.4314/njp.v43i3.13

[19] African Population and Health Research Centre (2015) Establishing Innovative Community Engagement Approaches in Baby Friendly Initiative: A Desk Review of Existing Practices.

http://www.Aphr.Org.wp-content/uploads/2015/03baby-friendly-community-initia tive-desk-review-fun-1.pdf 
[20] Moore, T., Gauld, R. and Williams, S. (2007) Implementing Baby Friendly Hospital Initiative Policy: The Case of New Zealand Public Hospitals. International Breastfeeding Journal, $2,8$.

[21] Bettinelli, M.E. (2012) Establishing the Baby Friendly Community Initiative in Italy. Journal of Human Lactation, 2, 297-303. https://doi.org/10.1177/0890334412447994

[22] Debes, A.K., Kohli, A., Walker, N., Edmond, K. and Mullany, L.C. (2013) Time to Initiation of Breastfeeding and Neonatal Mortality and Morbidity: A Systematic Review. BMC Public Health, 13, 819.

[23] Persad, M. and Mensinger, J.L. (2007) Maternal Breastfeeding Attitudes: Association with Breastfeeding Intent and Socio-Demographics among Urban Primiparous. Journal of Community Health, 33, 53-60. https://doi.org/10.1007/s10900-007-9068-2

[24] Arora, S., McJunkin, C., Wehrer, J. and Kuhn, P. (2000) Major Factors Influencing Breastfeeding Rates: Mother's Perception of Father's Attitude and Milk Supply. Pediatrics, 106, E67. http://www.paediatrics.org/cgi/content/full/106/5/e67

[25] Simard, I. (2005) Factors Influencing the Initiation and Duration of Breastfeeding among Low-Income Women Followed by the Canada Prenatal Nutrition Program in Four Regions of Quebec. Journal of Human Lactation, 21, 327-337. https://doi.org/10.1177/0890334405275831

[26] Earle, S. (2002) Factors Affecting the Initiation of Breastfeeding: Implications for Breastfeeding Promotion. Health Promotions International, 17, 204-214. https://doi.org/10.1093/heapro/17.3.205

[27] Forster, D.A. and McLachlan, H.L. (2007) Breastfeeding Initiation and Birth Setting Practices: A Review of the Literature. Journal of Midwifery and Women's Health, 52, 273-280. https://doi.org/10.1016/j.jmwh.2006.12.016

[28] Ford, K.A. and Miller, L.J. (2010) 2006-2007 North Metropolitan Perth Breastfeeding Cohort Study: How Long Are Mother's Breastfeeding? Breastfeeding Review Journal, 18, 14-24.

[29] Hundalani, S.G., Braitman, L.E., Matam, L.E., Matam, R. and Mandakovic-Falconi, S. (2013) Breastfeeding among Inner-City Women: From Intention before Delivery to Breastfeeding at Hospital Discharge. Breastfeeding Medicine, 8, 68-72. https://doi.org/10.1089/bfm.2012.0004

[30] Kitano, N., Nomura, K., Kido, M., Murakami, K., Ohkubo, T., Ueno, M. and Sugimoto, M. (2016) Combined Effects of Maternal Age and Parity on Successful Initiations of Exclusive Breastfeeding. Preventive Medicine Reports, 3, 121-126.

[31] Ekstrom, A.M., Widstrom, A.M. and Nissen, E. (2003) Duration of Breastfeeding in Swedish Primiparous and Multiparous Women. Journal of Human Lactation, 19 , 172-178. https://doi.org/10.1177/0890334403252537

[32] Guo, S., Fu, X., Scherpbier, R.W., Wang, Y., Zhou, H., Wang, X., et al. (2013) Breastfeeding Rates in Central and Western China in 2010: Implications for Child and Population Health. Bulletin of the World Health Organization, 91, 322-331. https://doi.org/10.2471/BLT.12.111310

[33] Prior, E., Santhakumaran, S., Gale, C., Philips, L.H., Modi, N. and Hyde, M.J. (2013) Breastfeeding after Caesarean Delivery; a Systematic Review and Meta-Analysis of World Literature. The American Journal of Clinical Nutrition, 95, 113-135.

[34] Seed, G., Fakhar, S., Imran, T. and Abbas, L.K. (2011) The Effect of Modes of Delivery on Infant's Feeding Practices. Iranian Journal of Medical Sciences, 36, 128-132.

[35] National Institute of Health Development (2010) Conference Statement on Vaginal 
Birth after Caesarean: New Insights, March 8-10, 2010. Seminars in Perinatology, 34, 351-365.

[36] Smith, E.R., Hurt, L., Choudhury, R., Sinha, B., Fawzi, W. and Edmond, K.M. (2017) Delayed Breastfeeding Initiation and Infant Survival: A Systematic Review and Meta-Analysis. PLoS ONE, 12, oe0180722.

https://doi.org/10.1371/journal.pone.0180722

[37] Awi, D.D. and Alikor, E.A. (2006) Barriers to Timely Initiations of Breastfeeding among Mothers of Healthy Full Term Babies Who Deliver at the University of Port Harcourt Teaching Hospital. Nigerian Journal of Clinical Practice, 9, 57-64.

[38] Dashti, M., Scott, J.A., Edwards, C.A. and AI-Sughayer, M. (2010) Determinants of Breastfeeding Initiation among Mothers in Kuwait. International Breastfeeding Journal, 5, 7. http://www.internationalbreastfeedingjournal.com/content/5/2/7

[39] Tilahun, G., Degu, G., Azale, T. and Tigabu, A. (2016) Prevalence and Associated Factors of Timely Initiation of Breastfeeding among Mothers at Debre Berhan Town, Ethiopia: A Cross-Sectional Study. International Breastfeeding Journal, 11, 27.

[40] Chin, A.C., Meyers, L. and Magnus, J.H. (2008) Race, Education and Breastfeeding Initiations in Louisiana 2000-2004. Journal of Human Lactations, 24, 175-185. https://doi.org/10.1177/0890334408316074

[41] World Health Organization (WHO) (2002) Infant and Young Child Nutrition. 55th World Health Assembly, Geneva, 13-18 May 2002, 1-3. http://apps.who.int/gb/archive/pdf_files/WHA55/ewha5525.pdf 